\title{
Study On Oil Reservoir Productivity Performance Via Combination of Taguchi and BEM Analyses M. N. Mohamad Ibrahim ${ }^{1}$ and S. Shuib ${ }^{2}$ \\ ${ }^{1}$ School of Chemical Sciences, Universiti Sains Malaysia, 11800 Pulau Pinang, Malaysia, mnm@usm.my \\ ${ }^{2}$ School of Mechanical Engineering, Universiti Sains Malaysia, 14300 Nibong Tebal, Pulau Pinang, Malaysia
}

\begin{abstract}
The application of Taguchi Robust Design Technique (TRDT) coupled with the Boundary Element Method (BEM) in analyzing the productivity performance of an oil reservoir is presented in this paper. Several reservoir rock and reservoir fluid properties; i.e. permeability, thickness, porosity and viscosity, were chosen in this study. The BEM allows the overall simulation of reservoir performance to be made; whereas the use of TRDT allows us to rank the most influencing factor (property) that affects the productivity performance of the reservoir. Numerical values obtained from the BEM analysis will be used as input data for the TRDT statistical analysis. Results indicate that oil viscosity is the most important factor that affects the productivity performance of the oil reservoir followed by the thickness of the pay zone, the rock permeability and the rock porosity. Results of this study can be used by reservoir engineer in making the right choice of Enhanced Oil Recovery techniques that is the most suitable for the reservoir.
\end{abstract}

Keywords: Taguchi method, Boundary Element Method, reservoir rock properties, reservoir fluid property, oil reservoir productivity

\section{Introduction}

Depleting reserves and the ever-increasing demand for oil necessitate the need for increasing drilling activities. The demand for oil keeps increasing despite uncertainties in the world economy. This is not surprising since hydrocarbon fuels remain relatively cheap and practical as compared with other fuel sources such as electricity and nuclear. Therefore, the hunt for new oil fields prompts drilling of new wells. Drilling operation starts only when the prospect for hydrocarbon is commercially justified. This is due to the expensive drilling cost that may hit as high as USD 10 million per well.

Besides drilling new wells, most oil companies develop the existing wells that are no longer capable of producing profitable amounts of oil through natural reservoir drives by 
means of enhanced oil recovery (EOR). The basic purpose of EOR is to restore formation pressure and fluid flow to a substantial portion of a reservoir by injecting fluid into injection wells located in rock that has fluid communication with production wells $[1,2,3]$. Water flooding and gas injection are the two most common processes that have been produced in the petroleum industry. Other processes such as chemical flooding and thermal method are often called advanced EOR technique since these methods not only restore the formation pressure but also improve displacement of oil by reducing its viscosity. Therefore in general term, EOR can be defined as oil recovery processes other than primary recovery that is simply depends on the natural reservoir drives [4].

In this study, four reservoir properties are considered in the BEM analysis. They are reservoir rock permeability, net pay thickness, rock porosity and reservoir fluid viscosity. These parameters were considered because they are easily available and very crucial for any drilling operation. Rock permeability is a measure of the ability of a fluid to flow in a porous medium or rock. Net pay thickness is the thickness of producing zone. The measure of the space within a rock is called porosity while viscosity is a measure of the resistance of a liquid to flow $[5,6]$.

To be able to rank these parameters using Taguchi method based on their contributions toward the productivity performance of an oil reservoir would be helpful for a reservoir engineer in designing the next Enhanced Oil Reservoir program at his/her field. This is because one should know what parameter should be given high priority compared to others and what is the most suitable EOR method that one should use, which can act directly to improve the particular parameter.

\section{Taguchi Method}

In this study, Taguchi Robust Design Technique (TRDT) was used to rank factors that may affect the productivity of oil reservoir. The use of Taguchi orthogonal array helps to determine the minimum number of simulation runs needed to produce the most favorable output for a given set of factors. These factors are rock permeability, reservoir oil viscosity, thickness of net pay and reservoir rock porosity. The comparison between full factorial design and Taguchi design is shown in Table 1 . The orthogonal array $\mathrm{L}_{9}$ was used to study the influence of these four factors. Each factor was considered at three levels. The factors involved and their levels are shown in Table 2. If full factorial experimental design were used, it would require $81\left(3^{4}\right)$ trials runs for all possible combinations of these factors to get the optimum result [7]. By using the Taguchi orthogonal array $\mathrm{L}_{9}$ for experimental design, the number of trials runs was reduced to 9 simple and effective experiments. The $\mathrm{L}_{9}$ array was chosen in this study since four factors at three levels case was analyzed in this paper. Different factor-level combination would require different array that can be found in most of books written about Taguchi method. 
Table 1 - Comparisons of factorial design and Taguchi design

\begin{tabular}{|c|c|c|c|}
\hline \multirow{2}{*}{ Factors } & \multirow{2}{*}{ Level } & \multicolumn{2}{|c|}{ Total number of experiments } \\
\cline { 3 - 4 } & & Factorial design & Taguchi design \\
\hline 2 & 2 & $4\left(2^{2}\right)$ & 4 \\
3 & 2 & $8\left(2^{3}\right)$ & 4 \\
4 & 2 & $16\left(2^{4}\right)$ & 8 \\
7 & 2 & $128\left(2^{7}\right)$ & 8 \\
15 & 2 & $32,768\left(2^{15}\right)$ & 16 \\
4 & 3 & $81\left(3^{4}\right)$ & 9 \\
\hline
\end{tabular}

Table 2 - Design factors and their levels for orthogonal experiment

\begin{tabular}{|c|l|c|c|c|}
\hline Colum & \multicolumn{1}{|c|}{ Factors } & \multicolumn{3}{|c|}{ Level Number } \\
\cline { 3 - 5 } n & & $\mathbf{1}$ & $\mathbf{2}$ & $\mathbf{3}$ \\
\hline 1 & Permeability (md), $\mathrm{k}$ & 50 & 100 & 150 \\
2 & Viscosity (cp), $\mu$ & 0.5 & 1 & 1.5 \\
3 & Thickness (feet), $\mathrm{h}$ & 10 & 20 & 30 \\
4 & Porosity (fraction),, & 0.15 & 0.30 & 0.45 \\
\hline
\end{tabular}

Orthogonal arrays are not new and dated back many years. They are the basic of square games and many other games of strategy. There are numerous orthogonal designs available to choose from. Table 3 illustrates the orthogonal array $\mathrm{L}_{9}$ [7]. Note that $\mathrm{L}_{9}$ array is also written as $3^{4}$ where 3 represents level number while 4 represents the number of factor considered. Since there were four of three levels factors, these factors were assigned to all four columns in the $\mathrm{L}_{9}$ array with specific arrangement. For example in trial number 1 , the value for rock permeability, oil viscosity, net pay thickness and rock porosity is $50 \mathrm{md}, 0.5$ $\mathrm{cp}, 10$ feet and $0.15(15 \%)$ respectively. For trial number 2 , the value for permeability, viscosity, thickness and porosity is $100 \mathrm{md}, 1.0 \mathrm{cp}, 20$ feet and $0.3(30 \%)$ respectively. Nine trial simulation runs using the Boundary Element Oil Reservoir Simulation software [8, 9, 10] with particular combination of factor levels in the array were carried out. 
Table $3-\mathrm{L}_{9}\left(3^{4}\right)$ Orthogonal Array [7]

\begin{tabular}{|c|c|c|c|c|}
\hline \multirow{2}{*}{ Trial Number } & \multicolumn{4}{|c|}{ Column Number } \\
\cline { 2 - 5 } & $\mathbf{k}=\mathbf{1}$ & $\boldsymbol{\mu}=\mathbf{2}$ & $\mathbf{h}=\mathbf{3}$ & $\boldsymbol{\emptyset}=\mathbf{4}$ \\
\hline 1 & 1 & 1 & 1 & 1 \\
2 & 1 & 2 & 2 & 2 \\
3 & 1 & 3 & 3 & 3 \\
4 & 2 & 1 & 2 & 3 \\
5 & 2 & 2 & 3 & 1 \\
6 & 2 & 3 & 1 & 2 \\
7 & 3 & 1 & 3 & 2 \\
8 & 3 & 2 & 1 & 3 \\
9 & 3 & 3 & 2 & 1 \\
\hline
\end{tabular}

\section{Boundary Element Method}

The software was developed based on the assumption of a hypothetical twodimensional homogeneous reservoir $S$ having NSS sources and/or sinks located randomly within an arbitrarily shaped reservoir. The following assumptions were used in developing the theory: a) the reservoir is in steady-state flow with reservoir pressure above bubble points i.e. undersaturated condition; b) single phase fluid having small (and constant) compressibility and constant viscosity is flowing in the system; c) the reservoir has a uniform thickness and it has a finite boundary; and d) gravitational effects are negligible.

The differential equation describing the unknown functions i.e. pressure, at all points in the reservoir is obtained by the introduction of Darcy's law into the continuity equation. By imposing the conditions and assumptions stated above, the differential equation describing the pressure distribution in the reservoir is [11, 12]:

$$
\frac{\partial^{2} p}{\partial X^{2}}+\frac{\partial^{2} p}{\partial Y^{2}}+\frac{\mu}{k} \sum_{m=1}^{N S S} q_{m} \delta\left(X-X_{m}, Y-Y_{m}\right)=0
$$

where $p$ is pressure, $\mu$ is the dynamic viscosity of the fluid, $k$ is the permeability, $q_{m}$ is the flow rate of the $m^{\text {th }}$ well per unit area (positive for injectors and negative for producers), $\delta$ is the Dirac delta function, $X, Y$ are coordinates axes, and $X_{m}, Y_{m}$ are coordinates of the $m^{\text {th }}$ source and/or sink where $m$ goes from 1 to NSS. 
Equation (1) can be transformed into an integral equation by multiplying it with the free-space Green's function and integrating it twice by parts. The free-space Green's function is also called the fundamental solution $[11,12,13]$ and is given as:

$$
G=\frac{1}{2 \pi} \ln \left(\frac{1}{r}\right)
$$

where $r$ is the distance between a field point $(X, Y)$ and a point of application of a unit charge $\left(X_{C}, Y_{C}\right)$. After standard manipulation [11], Equation (1) then becomes:

$$
\begin{gathered}
\alpha p\left(X_{i}, Y_{i}\right)=\frac{1}{2 \pi} \sum_{j=1}^{N} \frac{\partial p}{\partial n_{j}} \int_{s j} \ln \left(\frac{1}{r_{i}, j}\right) d s- \\
\frac{1}{2 \pi} \sum_{j=1}^{N} p_{j} \int_{s j} \frac{\partial}{\partial n}\left[\ln \left(\frac{1}{r_{i}, j}\right)\right] d s+\frac{1}{2 \pi} \frac{\mu}{k} \sum_{m=1}^{N S S} q_{m} \ln \left(\frac{1}{r_{i}, m}\right)
\end{gathered}
$$

where the boundary of the reservoir is divided into $N$ constant elements with constant properties as shown in Figure 1. The variable $\alpha$ is the included angle at the $i^{\text {th }}$ pivot point. It is assigned a value of $1 / 2$ when the pivot point is on a smooth boundary (i.e. not on a corner), and a value of 1 when the pivot point is inside the problem domain. For simplicity, let

$$
\begin{gathered}
G_{i, j}=\frac{1}{2 \pi} \int_{s j} \ln \left(\frac{1}{r_{i}, j_{j}}\right) d s \\
H_{i, j}=\frac{1}{2 \pi} \int_{s j} \frac{\partial}{\partial n}\left[\ln \left(\frac{1}{r_{i},{ }_{j}}\right)\right] d s \\
G S S_{i, m}=\frac{1}{2 \pi} \ln \left(\frac{1}{r_{i}, m}\right)
\end{gathered}
$$




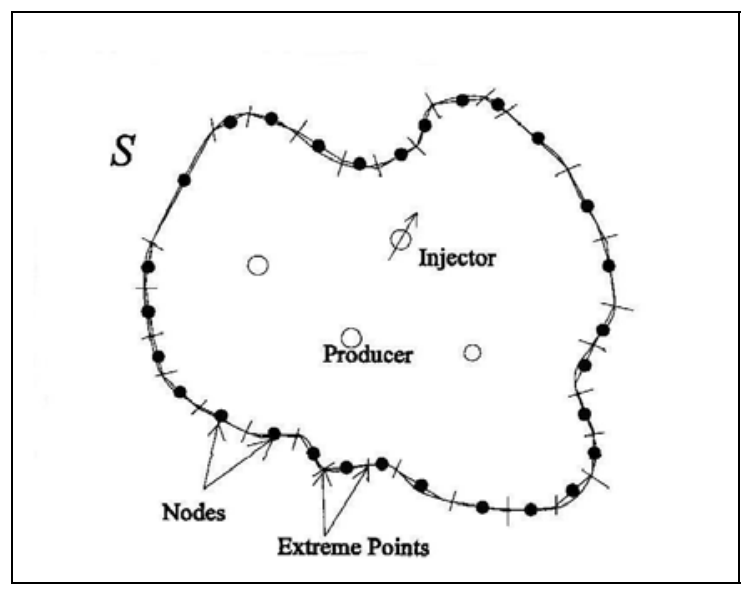

Figure 1. Reservoir having NSS sources and sinks where its boundary is divided into $N$ segments or elements

where $X_{i}, Y_{i}$ are coordinates of any pivot point, $r_{i, j}$ is the distance between the pivot point and the $j^{\text {th }}$ element where $j$ runs from 1 to $N$, and $r_{i, m}$ is the distance between the pivot point and the $m^{\text {th }}$ source and/or sink. Equation (3) now simplifies to:

$$
\alpha p\left(X_{i}, Y_{i}\right)=\sum_{j=1}^{N} \frac{\partial p}{\partial n_{j}} G_{i, j}-\sum_{j=1}^{N} p_{j} H_{i, j}+\sum_{m=1}^{N S S} q_{m} G S S_{i, m}
$$

The boundary of the reservoir, $S$, can be of the type $S_{p}$ or $S_{d p / d n}$ or a combination of the two types. Over the $S_{p}$ type boundary, the pressure $p$ is specified as constant throughout the element while $d p / d n$ is unknown. Over the $S_{d p / d n}$ type boundary, the $d p / d n$ is prescribed as constant and the pressure $p$ is unknown. In the field, pressure usually obtained from drill stem test (DST) data, which is conducted to every newly drilled well; whereas $d p / d n$ value is assigned to zero if the reservoir boundary falls on the fault. Similarly, the sources and/or sinks can also have known and unknown rates. For the known flow rate well, the well-bore pressure, $p_{w}$ is unknown and for the unknown flow rate well, the well-bore pressure is prescribed.

The idea is to apply Equation (7) at all the boundary nodes $(\alpha=1 / 2)$, as well as at all the source and/or sink locations $(\alpha=1)$. By doing so, a system of $N+N S S$ equations with $N+N S S$ unknown can be obtained and simplified to matrix form as follows: 


$$
\text { [HGGSS] } \stackrel{N}{U}=\stackrel{\mu}{A}
$$

where [HGGSS] consist of the coefficients $H, G$ and GSS. The vector $\stackrel{N}{U}$ contains all the $N+N S S$ unknowns of $p, d p / d n, p_{w}$ and $q$ and $\stackrel{\mu}{A}$ is a vector containing all the known values.

The above formulations had been validated elsewhere [8, 9, 10] against Muskat's two-dimensional analytical expressions [14] for the productivity of several well clusters located in a circular shaped reservoir. He uses an average external pressure instead of the actual external pressure in calculating the flow rates of the wells. Furthermore, Muskat also uses the same well-bore pressure for every well.

\section{Results and Discussion}

The results of the nine trial conditions are shown in Table 4. These simulation results are for the case of the following circular oil reservoir with single production well having the following properties:

$$
\begin{aligned}
& \text { Area }=314.2 \times 10^{6} \mathrm{feet}^{2}=7,212 \text { acre (reservoir area), } \\
& r_{w}=0.25 \mathrm{feet}(\text { well-bore radius), } \\
& \rho=62.4 \mathrm{lb} / \mathrm{ft}^{3} \text { (reservoir fluid density), } \\
& p_{w}=100 \mathrm{psi} \text { (well-bore pressure), } \\
& p_{e}=2,000 \mathrm{psi}(\text { external reservoir pressure) and } \\
& \text { Scale }=1: 5,000
\end{aligned}
$$

In the Taguchi analysis, there are three types of quality characteristics with respect to the target design, they are 'smaller is better', 'nominal is better' and 'bigger is better' [15]. In this study, the high value of oil production is desirable, therefore the 'bigger is better' quality characteristic was chosen. Since in this study we could expect the same result for the repeated trial (results generated from computer simulation), therefore the results cannot be transformed into signal to noise ratio.

The average of the factors for each level were shown in Table 5. For example, the porosity factor was at level 3 for trial condition 3, 4 and 8 in the $L_{9}$ array. In other words, number 3 appeared at trial 3, 4 and 8 in Column 4 of Table 3 . Therefore the computation for average effect of porosity at level 3 (number that appeared at the last row of column 5 of Table 5), which denoted by $\mathrm{m}_{\varnothing 3}$ is shown below: 


$$
\begin{aligned}
m_{\sigma 3} & =1 / 3\left(R_{T 3}+R_{T 4}+R_{T 8}\right) \\
& =1 / 3(1270.199+5080.9+1905.3) \\
& =2752.133
\end{aligned}
$$

where $\mathrm{R}_{\mathrm{T} 3}, \mathrm{R}_{\mathrm{T} 4}$, and $\mathrm{R}_{\mathrm{T} 8}$ were the values in the Table 4 corresponding to trial number 3,4 and 8 . The others were computed in the same manner as $\mathrm{m}_{\varnothing 3}$.

Table 4 - Simulation Results

\begin{tabular}{|c|c|}
\hline \multirow{2}{*}{ Trial Number } & $\begin{array}{c}\text { Total Oil Production in barrel per day } \\
\text { (bbl/d) }\end{array}$ \\
\cline { 2 - 2 } & $\mathbf{R}_{\mathbf{T}}$ \\
\hline 1 & 1270.199 \\
\hline 2 & 1270.199 \\
\hline 3 & 1270.199 \\
\hline 4 & 5080.9 \\
\hline 5 & 3810.7 \\
\hline 6 & 846.8 \\
\hline 7 & 11432.0 \\
\hline 8 & 1905.3 \\
\hline 9 & 2450.4 \\
\hline Grand average & 3259.633 \\
\hline
\end{tabular}

Table 5 - The Average Effects of Factor for Each Level

\begin{tabular}{|c|l|c|c|c|}
\hline Column & \multicolumn{1}{|c|}{ Factors } & \multicolumn{3}{|c|}{ Level Number } \\
\cline { 3 - 5 } & & $\mathbf{1}$ & $\mathbf{2}$ & $\mathbf{3}$ \\
\hline 1 & Permeability (md), $\mathrm{k}$ & 1270.199 & 3246.133 & 5262.566 \\
2 & Viscosity (cp), $\mu$ & 5927.699 & 2328.733 & 1522.466 \\
3 & Thickness (feet), $\mathrm{h}$ & 1340.766 & 2933.833 & 5504.300 \\
4 & Porosity (fraction),$\varnothing$ & 2510.433 & 4516.333 & 2752.133 \\
\hline
\end{tabular}


Different factors affect the deposition rate to different degrees. The relative effect of the different factors can be obtained by the decomposition of total variation into its appropriate components, which is commonly called analysis of variance (ANOVA). ANOVA is also needed for estimating the error variance. The results of ANOVA are shown in Table 6. Column 4 in the ANOVA table was defined as Sum of Squares. For example, sum of squares due to porosity factor was computed using the following formula:

$$
\begin{aligned}
S S_{\sigma}= & 3\left(m_{\theta 1}-m\right)^{2}+3\left(m_{\theta 2}-m\right)^{2}+3\left(m_{\theta 3}-m\right)^{2} \\
\mathrm{SS}_{ø}= & 3(2510.433-3259.633)^{2}+3(4516.333-3259.633)^{2} \\
& \quad+3(2752.133-3259.633)^{2} \\
= & 7194457.734
\end{aligned}
$$

where $\mathrm{m}_{\varnothing 1}, \mathrm{~m}_{\varnothing 2}$ and $\mathrm{m}_{\varnothing 3}$ refer to the average effects correspond to porosity factor for each level as listed in Table 5 and $\mathrm{m}$ is the grand average value as listed in Table 4. Sum of square of other factors were computed in the same manner and respectively tabulated in the same column. The variance of each factor was determined by dividing sum of square for each factor with its degree of freedom associated with a factor equals to one less than the number of levels. For a factor with 3 levels, level 1 data can be compared with level 2 and level 3 data but not level 1 itself. Thus the 3 levels factor has 2 DOF. The variance ratio (F) is the ratio of variance due to the effect of a factor and variance due to the error term.

Table 6 - ANOVA table

\begin{tabular}{|c|l|c|c|c|c|}
\hline Column & Factors & DOF & Sum of Squares & Variance & Percent \\
\hline 1 & Permeability (md) & 2 & 23909295.850 & 11954647.925 & 26.392 \\
2 & Viscosity (cp) & 2 & 33008700.598 & 16504350.299 & 36.436 \\
3 & Thickness (feet) & 2 & 26480181.115 & 13240090.557 & 29.229 \\
4 & Porosity (fraction) & 2 & 7194457.734 & 3597228.867 & 7.941 \\
\hline
\end{tabular}

The review of the 'Percent' column in Table 6 showed that the oil viscosity factor contributed the highest percentage $(36.4 \%)$ to the factor effects; followed by the net pay thickness $(29.2 \%)$, rock permeability $(26.4 \%)$ and rock porosity $(7.9 \%)$. Since the contribution of rock porosity was the smallest and less than $10 \%$ therefore it was considered insignificant. Thus, this factor was pooled (combined) with the error term. This process of disregarding the contribution of a selected factor and subsequently adjusting the contribution of the other factor is known as pooling. The new ANOVA after pooling is 
shown in Table 7. It was observed that as the smallest factor effect (porosity) was pooled, the percentage contributions of the remaining factors decreased slightly, but the ranking of factor effects still remained the same. In estimating the performance at optimum condition, only the significant factors were used. An examination of the average effects as shown in Table 5 indicates that level 1 of viscosity and level 3 of both permeability and thickness factors will be included in the optimum condition (after excluding the porosity factor). This is due to the highest value of average effects for each factor.

Table 7 - Pooled ANOVA table

\begin{tabular}{|c|l|c|c|c|c|}
\hline Column & Factors & DOF & $\begin{array}{c}\text { Sum of } \\
\text { Squares }\end{array}$ & Variance & Percent \\
\hline 1 & Permeability & 2 & 23909205.850 & 11954647.925 & 18.450 \\
2 & Viscosity & 2 & 33008700.598 & 16504350.299 & 28.494 \\
3 & Thickness & 2 & 26480181.115 & 13240090.557 & 21.288 \\
4 & Porosity & $\{2\}$ & $\{7194457.734\}$ & & \\
\hline $\begin{array}{l}\text { All others/Error } \\
\text { Total }\end{array}$ & 2 & 7194463.392 & 3597231.696 & 31.768 \\
\hline
\end{tabular}

Note : Insignificant factorial effect is pooled as shown \{\}

Table 8 - Estimate of the Optimum Condition of Design

\begin{tabular}{|c|c|c|c|}
\hline Factors & Level Description & Level & Contribution \\
\hline Permeability & 150 & 3 & 2002.933 \\
Viscosity & 0.5 & 1 & 2668.066 \\
Thickness & 30 & 3 & 2244.666 \\
\hline \multicolumn{2}{|l}{ Contribution from all factors (total) } & 6915.664 \\
Current grand average of performance or Mean & 3259.633 \\
Expected result at optimum condition & & 10175.298 \\
\hline
\end{tabular}

Table 8 shows the expected value of $10,175 \mathrm{bbl} / \mathrm{d}$ for oil production that one should get when optimum condition is applied. Contribution of each factor is the different between the grand average value and the average effect of each factor correspond to its optimum level. For example, the contribution of viscosity factor is given as: 


$$
\begin{aligned}
C_{\emptyset} & =m_{\varnothing}-m \\
& =5927.669-3259.663 \\
& =2,668.066
\end{aligned}
$$

The expected value is the sum of the total contribution from all factors and the grand average value as shown below:

$$
\begin{aligned}
R_{\text {expected }} & =C_{k}+C_{\mu}+C_{h}+m \\
& =6915.664+3259.663 \\
& =10,175.298 \mathrm{bbl} / \mathrm{d}
\end{aligned}
$$

The expected value however, is smaller than the value obtained for the seventh trial $\left(\mathrm{R}_{\mathrm{T} 7}\right)$ as listed in Table $4(11,432 \mathrm{bbl} / \mathrm{d})$. This is because the calculation of the expected value does not include porosity factor at all. In other words, the contribution of porosity factor towards the oil production rate is totally ignored. Whereas in obtaining $\mathrm{R}_{\mathrm{T} 7}$ value, the BEM program does include porosity factor in the analysis. Therefore it can be concluded that, the porosity factor also contribute to the production of oil from reservoir even though it is small. Further analysis shows that (by keeping the viscosity, thickness and permeability at their optimum levels), regardless of any rock porosity value use in the simulation runs, the oil productivity values are still the same as shown in Table 9. This proves that porosity has small contribution towards the productivity of the reservoir.

Table 9 - Same Oil Production Value at Different Porosity Level

\begin{tabular}{|c|c|c|c|c|c|}
\hline $\begin{array}{c}\text { Trial } \\
\text { No. }\end{array}$ & Porosity & Permeability & Viscosity & Thickness & $\begin{array}{c}\text { Total Oil } \\
\text { Production } \\
\text { in barrel per } \\
\text { day (bbl/d) }\end{array}$ \\
\hline 1 & 0.15 & 150 & 0.5 & 30 & 11432.0 \\
\hline 2 & 0.30 & 150 & 0.5 & 30 & 11432.0 \\
\hline 3 & 0.45 & 150 & 0.5 & 30 & 11432.0 \\
\hline
\end{tabular}




\section{Conclusions}

The result of this study could be used as a rule of thumb for reservoir engineers in the field when quick approximations need to be made. Although in the real life case, one could never obtain the exact numerical values as presented in the paper, it is believed that the real life case would follow the same general trend as the results of this study.

Among four factors considered in this study, reservoir oil viscosity found to be the most influenced factor in producing oil from the reservoir. It is followed by the net pay thickness, rock permeability and rock porosity. Designing an Enhanced Oil Recovery technique that can improve the oil viscosity such as steam flooding would be a good idea in order to improve the productivity of the reservoir.

\section{Acknowledgements}

The authors would like to express their appreciation to Universiti Sains Malaysia for financial support of this project through a research grant. The first author also would like to thank his beloved wife, Azah and his two princes Mohamad Aiman Hamzah and Ahmad Zaid for their supports, sacrifices and patience throughout this project.

\section{References}

1. Craig, F. F. - "The Reservoir Engineering Aspects of Waterflooding”, Monograph Series, SPE, Richardson, Texas, 1971.

2. Gaucher, D. H., Lindley, D. C. - "Waterflood Performance in a Stratified FiveSpot Reservoir-A Scaled-Model Study”, Trans., AIME, 219, 208-215, 1960.

3. Suder, F. E., Calhoun, J. C. Jr. - "Waterlood Calculation", Drill and Prod.Prac., API, 260-270, 1946.

4. Koederitz, L. F., Harvey A. H., Honarpour M. - "Introduction to Petroleum Reservoir Analysis”, Gulf Publishing Company, 80-84, Houstan, Texas, 1989.

5. Craft, B. C., Hawkins, M. - “Applied Petroleum Reservoir Engineering”. Prentice Hall, New Jersey, 1990.

6. Blasingame, T. A., Johnston, J. L., Poe, R. D. Jr. - “ Properties of Reservoir Fluids”, Texas A\&M University, 1989. 
7. Roy, R. K. - "A Primer on the Taguchi Method", Van Nostrand Reinhold, New York, 1990.

8. Mohamad Ibrahim, M. N., Numbere, D. T. - "Boundary Element Analysis of The Productivity Of Complex Petroleum Well Configuration”, In Chen, C. S., Brebbia, C. A. and Pepper, D. (Eds), Boundary Element Technology XIII, WIT Press, Southampton, 25-34, 1999.

9. Mohamad Ibrahim, M. N., Numbere, D. T. - "Productivity Predictions for Oil Well Clusters Using A Boundary Element Method", J. of Physical Science, Vol.11, 148-157, 2000 .

10. Mohamad Ibrahim, M. N., Numbere, D. T. - "Boundary Shape Effects On the Productivity of Oil Well Clusters", In Boundary Element Technology XIV, Kassab A. and Brebbia C. A. (Eds), WIT Press, Southampton, 293-299, 2001.

11. Numbere, D. T., Tiab, D. - "An Improved Streamline-Generating Technique That Use the Boundary (Integral) Element Method", SPE Reservoir Engineering, 1061-1068, 1988.

12. Numbere, D. T. - "A General Streamline Modeling Technique for Homogeneous and Heterogeneous Porous Media with Applications to Steamflood Prediction”, Ph.D. dissertation, University of Oklahoma, Norman, 1982.

13. Brebbia, C. A. - "The Boundary Element Method for Engineers", John Wiley and Sons Inc., New York City, 1978.

14. Muskat, M. - "The Flow of Homogeneous Fluids Through Porous Media", McGraw-Hill Book Co., Inc., New York City, 1937

15. Roy, R. K. - "Design of Experiments Using the Taguchi Approach", John Wiley and Sons Inc., New York, 2001. 